Weert, J.C.M. van, Bolle, S., Dulmen, S. van, Jansen, J. Older cancer patients' information and communication needs: what they want is what they get? Patient Education and Counseling: 2013, 92(3), 388-397

\begin{tabular}{|l|l|}
\hline $\begin{array}{l}\text { Postprint } \\
\text { Version }\end{array}$ & 1.0 \\
\hline Journal website & $\underline{\text { http://www.sciencedirect.com/science/article/pii/S0738399113001201 }}$ \\
\hline Pubmed link & $\underline{\text { http://www.ncbi.nlm.nih.gov/pubmed/23602863 }}$ \\
\hline DOI & 10.1016/j.pec.2013.03.011 \\
\hline
\end{tabular}

This is a NIVEL certified Post Print, more info at http://www.nivel.eu

\title{
Older cancer patients' information and communication needs: What they want is what they get?
}

JULIA C.M. VAN WEERT ${ }^{\text {A, } * \text {, SIFRA BOLLE }}{ }^{\text {A }}$, SANDRA VAN DULMEN ${ }^{\text {B,C,D }}$, JESSE JANSEN ${ }^{\text {E }}$

\begin{abstract}
a Amsterdam School of Communication Research/ASCoR, University of Amsterdam, Amsterdam, The Netherlands

b NIVEL (Netherlands Institute for Health Services Research), Utrecht, The Netherlands

c Department of Primary and Community Care, Radboud University Nijmegen Medical

Centre, Nijmegen, The Netherlands

d Department of Health Sciences, Buskerud University College, Drammen, Norway

e Sydney School of Public Health, Centre for Medical Psychology and Evidence-Based

Decision-Making (CeMPED), University of Sydney, Sydney, Australia
\end{abstract}

\begin{abstract}
Objective: To evaluate what information and communication aspects older cancer patients ( $\leq 65$ ) consider important in preparing for chemotherapy treatment (CT), the extent to which this corresponds with what oncology nurses consider important, and the extent to which nurses attend to these aspects during real-life educational visits in oncology.

Methods: The QUOTE ${ }^{\text {chemo }}$ was used to have patients $(\mathrm{n}=116)$ and nurses $(\mathrm{n}=123)$ rate the importance of 66 aspects of patient education. Subsequently, the implementation of these 66 aspects during videotaped nursing visits $(n=155)$ with older cancer patients receiving CT for the first time was examined.

Results: Older cancer patients attached most importance to 'treatment-related information', 'rehabilitation information', 'affective communication' and discussing 'realistic expectations'. Nurses placed great importance to almost all aspects except to discussing 'realistic expectations'. Discrepancies were found between expressed importance and the actual performance during the videotaped consultations, particularly in discussing realistic expectations, coping information, interpersonal communication, and tailored communication.

Conclusion: Results pointed to aspects that need improvement to ensure high quality patient education tailored to the patients' needs.

Practice implications: To make sure older cancer patients' needs are met, more attention should be paid to the development of interventions supporting both needs assessment and fulfillment.
\end{abstract}


Weert, J.C.M. van, Bolle, S., Dulmen, S. van, Jansen, J. Older cancer patients' information and communication needs: what they want is what they get? Patient Education and Counseling: 2013, 92(3), 388-397

\section{INTRODUCTION}

Effective communication surrounding treatment is considered to be the key to good cancer care. However, health care professionals frequently lack the communication skills needed to identify patients' individual concerns and problems [1]. As a consequence, the information provided is often insufficiently tailored to the patients' information and communication needs, resulting in unmet needs (see Hack et al. [2], for a review). Cancer is frequently a disease of older adults and, due to population growth and aging, the number of new cancer patients is expected to double by the year 2050 [3,4]. Older cancer patients are physiologically, psychologically, socially, economically and culturally heterogeneous, which pose challenges to the care, including patient education, for this growing segment of the population [5]. Communication with older cancer patients can be complicated by various age-related barriers [6], such as cognitive decline [7], sensory impairments [8] and patients' beliefs, perceptions and knowledge about cancer [9]. Understanding older cancer patients' information and communication needs and the extent to which these needs are fulfilled is essential, because not being well informed may affect patient outcomes negatively. According to the Elaboration-Likelihood Model, personal relevant information, i.e. information that is tailored to the patients' needs, is processed more deeply and is therefore likely to improve knowledge and recall of information, i.e. remembering and reproduction [10-12]. This might, ultimately, contribute positively to patient satisfaction [13], treatment adherence [6,13-15], disease management, anxiety [16,17] and quality of life [18]. Although oncology patients in general continuously seem to have unmet needs [2] and unfulfilled information and communication needs influences quality of life more negatively in older compared to younger patients [18], little is known about the (unmet) information and communication needs of older cancer patients (_65 years). In a recent systematic review of unmet support needs, including information and communication needs, it was found that the level of unmet needs in newly diagnosed older cancer patients undergoing active treatment was high, and the most common unmet needs were information and psychological needs. However, in only three out of 30 studies included in this review, the mean age was in the 70s, and only one study focused on older adults exclusively [19]. In an earlier literature review, no study could be identified that specifically addressed older cancer patients' information and communication needs either [20]. Puts and colleagues [19] concluded that more research is needed that focuses on the needs of older adults specifically, as this is an understudied area. Since the level of unmet needs is highest after diagnosis and start of treatment [19,21], the current study focuses on needs fulfillment of older cancer patients in this particular stage of their disease. We choose to study chemotherapy treatment (CT), because CT is in the top-three of most used treatments for cancer [22]. Oncology nurses play an important role in patient education about CT by providing information about the treatment and (handling) potential side effects, especially at the beginning of CT. One of their tasks is to provide individualized instruction to patients newly diagnosed with cancer after a careful assessment of the patients' needs $[23,24]$. It can be assumed that the nurses' opinion on which aspects are, in general, important to discuss during educational sessions preceding CT will influence the content of the consultation. It is therefore striking that, as far as we are aware, no previous studies compared the patients' 
Weert, J.C.M. van, Bolle, S., Dulmen, S. van, Jansen, J. Older cancer patients' information and communication needs: what they want is what they get? Patient Education and Counseling: 2013, 92(3), 388-397

perspective with the nurses' perspective and with actual patient education during consultations. To take all these perspectives into account, we built on an approach called QUOTE (QUality Of care Through the patients' Eyes) [25-29]. According to this approach, quality of care is a multidimensional concept, based on a relationship between needs (or 'expectations') and performance (or 'experiences'), in the current study being defined as the degree to which the providers' information and communication performance meets the patients' needs. To gain insight in unmet needs two indicators are used: 'importance', i.e. how significant a specific health care aspect is to patients, and 'performance', i.e. the actual experience of patients with that aspect. QUOTE questionnaires are standardized and validated surveys in which patients' experiences with quality of care are conceptualized according to these importance and performance dimensions. When combined, these dimensions reflect what people see as desired qualities in health care [28,29]. Generally, both dimensions are assessed by self-reported patient questionnaires. However, previous research indicates that the relationship between perceived information provision and actual information provision is weak [30]. As we were interested in what had actually been discussed during the consultation, we decided to make use of video observations to examine the performance dimension. To summarize, this research aims to understand the information and communication needs of older cancer patients at the start of CT, the needs as perceived by their nurses, and the extent to which these needs are actually met during educational nursing visits in oncology. The study was conducted among cancer patients aged 65 years or older, because this cut-off point is frequently used to define older age [31,32].

\section{METHODS}

\subsection{Design}

The current study is part of a larger study in which the specific information and communication needs that have to be addressed in health education preceding CT in older cancer patients were examined, in order to develop and evaluate an intervention to improve the communication with older patients. The study was performed in twelve wards of ten Dutch hospitals. The main study used a randomized pre- and post-test design with measurements (i.e., video observations and questionnaires) at baseline (pre-test) and directly after the implementation of the intervention (posttest), with randomization at ward level. The control group of nurses continued in giving standard information. For the current study, only data from the control group (pre- and post-test) and the experimental group at pre-test were used. The Medical Ethical Committee of the University Medical Centre Utrecht, the Netherlands, granted permission for the study (trial number 04/ 184), supplemented by local feasibility statements from all participating hospitals.

\subsection{Subjects}

To be eligible for the study, patients had to meet the following inclusion criteria: (1) aged 65 years or older, (2) receiving CT for the first time or for the first time in 5 years, (3) not participating in a Phase III clinical trial, (4) sufficient mastery of the Dutch language, and (5) no non-age related cognitive impairment (according to the medical file). Eligible nurses had to meet the following criteria: (1) certified to 
Weert, J.C.M. van, Bolle, S., Dulmen, S. van, Jansen, J. Older cancer patients' information and communication needs: what they want is what they get? Patient Education and Counseling: 2013, 92(3), 388-397

provide oncology care and (2) providing patient education about CT as part of their regular employment duties. Temporary staff and students were not eligible.

\subsection{Procedure}

Before the consultation, written informed consent to videotape the consultation was given by patients and nurses. The consultation was videotaped using an unmanned camera. Immediately after the consultation, patients were asked to complete a questionnaire on background characteristics. A researcher was available to read the questions aloud, if necessary. After the consultation, nurses were asked how they had experienced being videotaped. Although most of them reported to have experienced some anticipatory tension, the stress generally disappeared once the consultation had started. Thus, the majority of nurses reported that the consultation reflected the normal situation. Six weeks after the consultation, participating patients received a second questionnaire, including the QUOTE-Importance questionnaire, in which patients were asked to rate the extent to which specific aspects of information and communication were considered important during the educational nurse consultation at the beginning of CT. All nurses that fulfilled the inclusion criteria received the same QUOTE ${ }^{\text {chemo }}$-Importance questionnaire at the beginning of the study. They were asked to attach importance to the same aspects of information and communication as older cancer patients (see Section 2.4.2).

\subsection{Measurements}

\subsubsection{Background characteristics}

The self-administered post-visit questionnaire for patients contained sociodemographic items inquiring about age, gender, education and living situation. Additional medical background characteristics (diagnosis, time since diagnosis and treatment goal) were obtained from the medical file. In addition, frailty was measured using the Groningen frailty indicator (GFI) [33,34]. The GFI contains 15 items and screens for the loss of functions and resources in four domains of functioning: physical (mobility functions, multiple health problems, physical fatigue, vision, hearing), cognitive (cognitive functioning), social (emotional isolation), and psychological (depressed mood and feelings of anxiety). A total score was counted (range 0-15). A score of 4 indicates moderate frailty and a higher score indicates more frailty [34].

\subsubsection{Unmet needs}

Needs fulfillment was measured by the QUOTE ${ }^{\text {chemo }}$. As there were no validated questionnaires available for the purpose of this study, the QUOTE ${ }^{\text {chemo }}$ was developed [35], in conformity with the QUOTE (QUality Of care Through the patients' Eyes) methodology [27-29]. The QUOTE ${ }^{\text {chemo }}$ consists of two parts, i.e. the

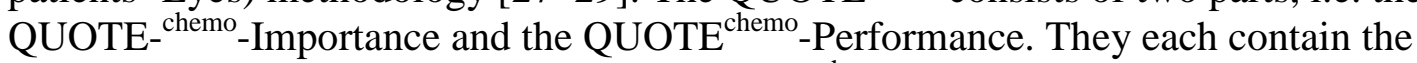
same 67 items. One item of the original QUOTE ${ }^{\text {chemo }}$ (i.e., 'discussion of all possible side-effects of treatments') was removed, because the performance of this item could not reliable been assessed as there are many different kind of CTs and the observers had no knowledge of all possible side-effects of each CT. This resulted in 66 items in this study. The QUOTE ${ }^{\text {chemo }}$-Importance was completed by older cancer patients to 
Weert, J.C.M. van, Bolle, S., Dulmen, S. van, Jansen, J. Older cancer patients' information and communication needs: what they want is what they get? Patient Education and Counseling: 2013, 92(3), 388-397

get insight in their information and communication needs surrounding CT and by nurses to get insight in the congruence between patients and nurses. The extent to which patients and nurses considered the 66 specific aspects of information and communication important at the beginning of CT ('needs') was assessed on a 4-point Likert scale ('not important', 'fairly important', 'important', 'extremely important'). The extent to which the nurses implemented the same 66 communication aspects during the consultation was rated by trained observers on a 4-point Likert scale ('not

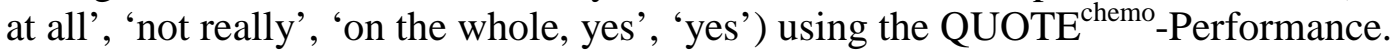
Nurses' performance was assessed by observing video recordings in order to have an objective rating. Five independent observers rated the video observations of the nursing encounters preceding chemotherapy. Interrater reliability (mean Cohen's Kappa) was 0.49 , which can be considered as moderate [36]. The 66 items of the QUOTE $^{\text {chemo }}$ were in a previous study [35] categorized in seven dimensions, i.e. three cancer-related categories: (1) treatment-related information (e.g., how treatment works, side-effects); (2) discussing realistic expectations/prognosis informa-tion (e.g., expected life span, discussing the future); (3) rehabilita-tion information (e.g., impact on activities of daily life, dealing with side effects at home) and four generic communication skills categories: (4) coping information (e.g., exploring the patients' feelings, how to get support); (5) interpersonal communication (e.g., being attentive to significant others, exploring their questions); (6) tailored communication (e.g., understanding the patients' personal circumstances and tailoring the information accordingly), and (7) affective communication (e.g., showing empathy, providing space for feelings and emotions). A validation study of the QUOTE ${ }^{\text {chemo }}$ in a different sample revealed good internal consistency, satisfactory item-total correlations and convergent validity. The development and psychometric properties of the QUOTE $^{\text {chemo }}$ are extensively described elsewhere [35]. Table 1 gives an overview of the QUOTE ${ }^{\text {chemo }}$ categories, their content and the Cronbach's alpha's of the QUOTE $^{\text {chemo}}-$ Importance and QUOTE ${ }^{\text {chemo}}$-Performance in the present study.

\subsection{Data analysis}

A non-response analysis between participants and non-participants and between

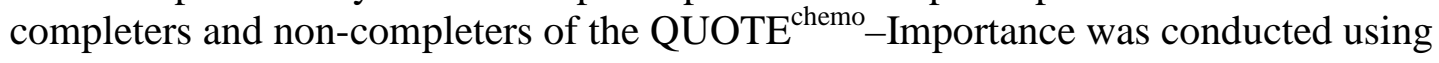
t-tests and Chi-square tests, where appropriate. Importance and Performance scores on the seven categories of the QUOTE ${ }^{\text {chemo }}$ were calculated as the mean of the scores on the relevant items (range of the subscales 1-4).

\section{[TABLE 1]}

Differences between, on the one hand, patients' scores on the QUOTE ${ }^{\text {chemo }}$ Importance and, on the other hand, nurses' scores on the QUOTE ${ }^{\text {chemo }}-$ Importance, and patients' performance scores were examined using ANOVAs. Quality impact indices (QIIs) were calculated, in line with earlier studies on QUOTE questionnaires, by multiplying the patients' importance score of the items with the fraction $(\% / 100)$ of consultations in which there was a lack of performance on that item, i.e. the item was 'not at all' (score 1) or 'not really' (score 2) discussed (importance score proportion lack of performance) [26]. A QII of 0.30 or more indicates a need for improvement (based on the criterion of minimal 10\% of the consultations with a lack of performance on an 'important item', i.e. importance score $=3$ ), and a QII of 1.0 or 
Weert, J.C.M. van, Bolle, S., Dulmen, S. van, Jansen, J. Older cancer patients' information and communication needs: what they want is what they get? Patient Education and Counseling: 2013, 92(3), 388-397

more shows a very clear need to be improved (based on the criterion of minimal one third of the consultations with a lack of performance on an 'important item', i.e. importance score $=3$, or minimal $25 \%$ of the consultations with a lack of performance on a 'very important item', i.e. importance score $=4$ ) [26]. All analyses were conducted in SPSS version 19. 3.

\section{RESULTS}

\subsection{Response}

In total, 361 patients were informed about the study and asked to give written consent. Eighteen patients did not meet the inclusion criteria and had to be excluded afterwards, leaving 343 eligible patients. Of these, 115 patients (33.5\%) refused to participate. They felt it was too much $(n=69)$, were too tired or too ill $(n=10)$, did not want to be videotaped $(n=16)$ or had other reasons $(n=20)$. Eighteen patients (5.2\%) could not be included due to logistical reasons (e.g. the ward forgot to forward the patient's name to the researchers, time schedule changed, traffic delay). In total, 210 older cancer patients (61.2\%) participated in the larger study and their consultations were videotaped. As we only used pre- and post-data of the control group and pre-test data of the experimental group, 55 (26.2\%) patients were excluded from analysis, because they were randomized to the experimental group at post-test. Of the resulting 155 patients, 116 (74.8\%) completed the QUOTE ${ }^{\text {chemo-Importance. }}$ The QUOTE ${ }^{\text {chemo}}$-Performance could be assessed for all 155 videotaped consultations. A non-response analysis revealed that non-participating patients were older $(\mathrm{M}=73.7, \mathrm{SD}=6.8)$ than participating patients $(\mathrm{M}=72.2, \mathrm{SD}=4.8 ; \mathrm{p}<.05)$. There were no differences in gender between participating and non-participating patients. Moreover, participating (videotaped) patients who did not complete the QUOTE $^{\text {chemo }}$-Importance were more frail $(\mathrm{M}=3.6, \mathrm{SD}=1.7$ vs $\mathrm{M}=2.1, \mathrm{SD}=1.9$; $\mathrm{p}$ $<.001)$ and more often living alone $(40.5 \%$ vs $15.7 \%$; $>$ .05$)$ than participating patients who fulfilled the QUOTE ${ }^{\text {chemo }}$-Importance. The majority (75.7\%) completed the questionnaire alone, $22.5 \%$ together with someone else. There were no other differences in background characteristics between non-completers and completers of the QUOTE ${ }^{\text {chemo }}$-Importance (see Table 2). In total, 141 nurses participated in the study. 77 (54.6\%) were videotaped as part of their regular employment duties. The QUOTE ${ }^{\text {chemo }}$-Importance was filled out by 123 nurses, 59 of whom (48.0\%) could be videotaped during one or more educational consultations preceding CT. Another 18 nurses were videotaped, but did not complete the QUOTE ${ }^{\text {chemo }}$-Importance.

\subsection{Background characteristics patients}

The majority of included patients was male (68.4\%) and lived with a partner $(71.9 \%)$. The mean age was 72.1 years $(\mathrm{SD}=4.5)$ and half of the respondents had a lower educational background (50.0\%). The mean frailty score was $2.4(\mathrm{SD}=1.9)$. Table 2 summarizes the socio-demographic and disease characteristics of included patients.

\subsection{Background characteristics nurses}

Table 3 shows the demographic characteristics of the nurses who completed the QUOTE $^{\text {chemo }}$-Importance. The majority of the nurses was female (93.4\%) with an average age of 41.0 years ( $\mathrm{SD}=8.1$ ). The average duration of the videotaped consultation was $55.3 \mathrm{~min}(\mathrm{SD}=15.7)$. 
Weert, J.C.M. van, Bolle, S., Dulmen, S. van, Jansen, J. Older cancer patients' information and communication needs: what they want is what they get? Patient Education and Counseling: 2013, 92(3), 388-397

\subsection{Unmet needs}

Fig. 1 shows the percentage of patients and nurses that rated specific aspects of cancer-related information and communication needs at category level as 'important' or 'very important' (mean score _ 2.5). A large proportion of patients (82.3\%) reported it is (very) important to receive 'treatment-related information'. Nurses endorsed this importance (81.4\%). Also 'rehabilitation information', i.e. information on how patients can deal with the side effects at home, was considered (very) important by a large number of patients (78.8\%). Nurses attached even greater importance to this category $(95.9 \% ; \mathrm{p}<.001)$. A large difference between patients and nurses was found in the category 'realistic expectations'. Two thirds of the patients (67.7\%) found it (very) important that topics that have to do with the prognosis and the future are discussed with the nurse, but nurses attached significantly lower importance to these aspects $(16.8 \%)$. Results on the QUOTE ${ }^{\text {chemo }}$ Performance show that patients' needs with respect to 'treatment related information' were on average quite properly met. However, aspects regarding 'rehabili-tation information', considered as important by both patients and nurses, were on average in less than forty percent (38.1\%) of the consultations moderately or maximally discussed (score 3 or 4). For 'realistic expectations', this was the case in only 3.2\% of the consultations. Fig. 2 shows the results in relation to the generic information and communication needs categories. All four categories were found (very) important by a large majority of nurses (range $81.1 \%$ for 'coping information' to 99.2\% for 'affective communication'). Although a considerable amount of patients considered these categories also as (very) important (range $44.1 \%$ for 'coping information' to $79.1 \%$ for 'affective communication'), they attached significantly less value to these aspects than nurses. With regard to performance, or the extent to which aspects of the four categories were actually addressed during the consultations, the patients' needs for 'affective communication' were properly fulfilled (84.5\%). However, there was on average little 'interpersonal communication with relatives' (20.6\%), the con-sultations were hardly personally 'tailored to the patients' circumstances' (3.2\%), and there was little attention for discussing how the patient can 'cope with the disease' (5.8\%). The difference between patients' and nurses' mean importance scores on the one hand and performance scores on the other hand are statistically significant $(\mathrm{p}<.001)$. Table 4 shows the mean importance scores of nurses and patients as well as the mean performance scores for each category and individual items. As was already shown by Figs. 1 and 2, aspects from the categories 'treatment-related information', 'rehabilitation information', 'affective communication' and dis-cussing 'realistic expectations' were generally considered most important by patients. Nurses attached great importance to all categories, with the highest scores on 'affective communication', 'rehabilitation information', 'tailored communication' and 'inter-personal communication'.

\section{[TABLE 2] [TABLE 3] [TABLE 4] [FIGURE 1] [FIGURE 2]}

Quality impact indices (QII) were calculated by combining importance scores of patients (needs) with performance scores. All QUOTE ${ }^{\text {chemo }}$ categories, except for 'affective communication', showed a mean QII of 1.00 or higher, indicating a need for improvement. The biggest gap between needs and experience was found for discussing 'realistic expectations' $(\mathrm{QII}=2.59)$. Further-more, 'coping information' 
Weert, J.C.M. van, Bolle, S., Dulmen, S. van, Jansen, J. Older cancer patients' information and communication needs: what they want is what they get? Patient Education and Counseling: 2013, 92(3), 388-397

$(\mathrm{QII}=1.79)$, ‘interpersonal communication' $(\mathrm{QII}=1.73)$ and 'tailored communication’ $(\mathrm{QII}=1.72$ ) showed high potential for improvement. At item level, the biggest incongruence was found in the individual items 'what will happen if patient chooses not to start treatment' $(\mathrm{QII}=2.98)$, 'asking how much information the patient would like to know' $(\mathrm{QII}=2.74)$, 'explaining emotional reactions on CT' $(\mathrm{QII}=2.71)$, 'checking whether the patient still wants to start CT after being educated' $(\mathrm{QII}=2.65)$, 'sufficient information about what is going on' $(\mathrm{QII}=2.48)$ and 'checking the patients' expectations' $(\mathrm{QII}=2.46)$.

\section{DISCUSSION AND CONCLUSION}

\subsection{Discussion}

Older cancer patients attached the most importance to 'treatment-related information', 'rehabilitation information' (i.e., the impact of treatment on daily life and how to deal with side effects at home), 'affective communication' and discussing 'realistic expectations'. Nurses highly valued almost all aspects except discussing 'realistic expectations'. Although both patients and nurses placed great importance to certain aspects, results pointed to impressive discrepancies between perceived importance and performance during actual consultations. The highest need for improvement was found for discussing 'realistic expectations', 'coping information', 'interpersonal communication' and 'tailored communication'. The results regarding needs are in line with other studies using the QUOTE ${ }^{\text {chemo }}$ among a heterogeneous sample of 345 cancer patients with a mean age of 55.7 years (range 20-84) [35] resp. 960 cancer patients with a mean age of 57.0 (range 18-100) [37]. In both studies, 'treatment-related information', 'affective communication' and 'rehabilitation information' were perceived most important by patients [36,37], and in the study of Bolle et al. [37] discussing 'realistic expectations' was also one of the most prevalent needs. In the latter study, no differences were found between younger $(<65)$ and older ( $\leq 65$ ) patients, except for 'affective communication', which was found to be even more important for older than for younger patients [37]. The literature demonstrates that a patient-centred approach to communicating with older cancer patients should take place in the context of a caring, continuous relationship [6]. Also, a good atmosphere during the consultation, emotional support, the feeling there is a bond of trust and a safe environment have earlier been described as a prerequisite for older patients to be able to reflect on the information and to process the information cognitively [38]. In both of these previous studies, the highest need for improvement was found for discussing 'realistic expectations', 'rehabilitation information' and 'interpersonal communication' [36,37]. However, in the current study 'coping information' and 'tailored communication' needs were more often unmet than 'rehabilitation information' and 'affective communication'. Also, all quality impact indices were (much) higher in the present study. The previous studies both assessed performance by self-reported measurements, while in the current study video observations of actual consultations were used, which might explain the difference. For instance, independent observers might judge the extent to which the communication was tailored to individual characteristics of the patient as minimal, while the patients might experience the same consultation as sufficiently tailored to their situation. In previous research it was also concluded that the assessment of actual communication by independent observers not fully reflects the patients' 
Weert, J.C.M. van, Bolle, S., Dulmen, S. van, Jansen, J. Older cancer patients' information and communication needs: what they want is what they get? Patient Education and Counseling: 2013, 92(3), 388-397

perceived experience. Patients probably judge the information and communication during consultations on other factors than what actually has been discussed, such as their relation with the caregiver, comprehensiveness of the information and communication expectations in general [30]. Thus, it is important to be aware of differences between perceived performance and actual performance, before deciding which measurement is most appropriate concerning the study goals. In the current study, we choose for objective video observations as older adults are expected to underreport their unmet needs [19]. Another explanation might be found in the time at which the survey was conducted. In the current study, patients fulfilled the questionnaire six weeks after the start of treatment, while in the previous studies CT started on average 6.7 months [36] resp. 5.7 years [37] ago. This means that there was a different time lag between the start of CT and patients filling out the questionnaire. It is known that needs change across the cancer care continuum [2,19], but it might also be possible that memories change when the event, i.e. the educational consultation at the start of CT, was longer ago. The results of these retrospective studies might be dissimilar from the immediate outcomes when directly assessed before, after or during the consultation [38]. Future studies should initiate measurement of patients' needs at the time of diagnosis and follow patients throughout their cancer journey to ascertain important changes in information needs over time [36,41]. In the current study, the QII was especially high for discussing 'realistic expectations'. It is known that health care professionals seem to experience difficulties in discussing topics that have to do with prognosis, especially when it concerns bad news $[39,40]$. However, it is particularly noticeable that most nurses placed very little importance to discussing topics regarding the future, prognosis and realistic expectations, while two thirds of the patients attached (much) value to talking about these topics with their nurse. Apparently, oncology nurses do not consider discussing these aspects as their task. The role of the caregiver in prognosis communication has not been well studied [42], and as far as we are aware, hardly any research focused on task definition of physicians and nurses in communicating 'realistic expectations' at the start of treatment. We know from research on end-oflife decisions that increased clarity about the role of nurses is needed [43], and this might also count for the start of treatment. The difference between nurses and physicians is that physicians are legally responsible for making decisions [43] and it is their formal task to communicate the exact prognosis. However, this does not mean that nurses cannot play a significant role in discussing topics that have to do with the prognosis, such as talking about the future, checking the patients' expectations or giving advice. Although guidelines have been developed to assist physicians in prognosis communication [44], it is recommended to develop additional guidelines describing the role of nurses, including how and to which extent to communicate prognosis information and realistic expectations sensitively and effectively. Not talking at all about the prognosis might be a missed opportunity, as has been stated by Mills and Sullivan [45, p. 633]: "Without nursing involvement, many patients will not truly understand their illness, prognosis, or treatment options, and this could seriously hinder, and indeed adversely affect, their recovery', The other categories in which high QIIs were found, were all generic communication skills categories, i.e. 'coping information', 'interpersonal communication' and 'tailored communication'. This indicates that there seems to be more room for improvement in generic communication skills than in providing cancer-specific 
Weert, J.C.M. van, Bolle, S., Dulmen, S. van, Jansen, J. Older cancer patients' information and communication needs: what they want is what they get? Patient Education and Counseling: 2013, 92(3), 388-397

content information, which might also apply to other fields than cancer care. Results regarding ‘interpersonal communication' and ‘tailored communication' are in line with previous studies. Although the need for interpersonal communication has hardly been assessed in older cancer patients, family members of breast cancer patients in general are found to have substantial needs for information (see Rees and Bath, [46] for a review), informal caregivers of cancer patients would like more professional attention [47], and spouses of breast cancer patients were not content with available information [48]. In the latter study, age was not associated with a perception of sufficient information [48]. The need for 'tailored communication' has been recognized in older cancer patients $[6,18]$. Especially eliciting the patients' expectations is considered vital to attaining concordance between older cancer patients and physicians [6]. Results regarding 'coping information' suggest room for improvement for older cancer patients. However, the need for 'coping information' by older cancer patients requires more research. Although Puts et al. [19] reported psychological care as one of the highest unmet needs in older cancer patients, several studies suggest that cancer and its treatment has a greater psychological impact on younger than on older patients, indicating that older cancer patients are better able to cope with serious illness than younger ones [49-52]. As well informed older ( 65 years) cancer patients showed a better ability to cope with psychological and emotional assumptions of their disease and treatments [53], this topic is worth additional research. The present study has been conducted in a sample of nurses. It would be interesting to know whether the results can be transferred to other professionals such as physicians. A previous study comparing the information priorities of prostate cancer patients to those of their health-care professionals (nurses, physicians and radiation therapy technologists) concluded that each professional groups significantly more agreed with the other professional groups than they agreed with patients [54,55]. The findings of the current study confirm that professionals cannot assume that their own information and communication priorities are the same as those of their patients [54]. However, despite the between-group similarity between professional groups in previous research, opinions varied widely within each profession [55,56] in two different countries [56]. Although these studies suggest that the nurses' opinions in the current study might in general be comparable with those of physicians, professionals in general seem to vary substantially in the information that they deem essential to discuss, which has important implications for patients. It seems therefore important to develop strategies for improving the equity of information provision [55]. It must be noted that the mean frailty score of participants in this study was 2.4. Considering patients with a frailty score of 4 or higher as moderately frail [34], we can conclude that the majority of included patients was not or only a little frail. As we used a convenient sample from ten hospitals, we have no indications that our sample was biased. The frailty scores suggest that CT was offered to a relatively 'healthy population'. This idea is supported by literature, particularly regarding curative CT. For instance, while a large majority of younger patients with stage III colon cancer receives adjuvant CT, many older patients with the same stage of cancer do not get this treatment. The most common motives for withholding CT are a combination of high age, co-morbidity and poor performance status [57], all indicators for frailty. In the current study, the patients who did not complete the QUOTE ${ }^{\text {chemo }}$ - Importance were more frail $(\mathrm{M}=$ 3.6) than completers $(M=2.1)$, although they still were only moderately frail (i.e. 
Weert, J.C.M. van, Bolle, S., Dulmen, S. van, Jansen, J. Older cancer patients' information and communication needs: what they want is what they get? Patient Education and Counseling: 2013, 92(3), 388-397

below the cut-off point of 4.0). It might therefore be possible that information and communication needs of older cancer patients who are more frail differ from the needs that are reported in the current study.

\subsection{Conclusion}

Increasing insight into individual (unmet) needs may help health care providers to better tailor their communication to cancer patients' needs. 'Treatment-related information', 'rehabilitation information', 'affective communication' and discussing 'realistic expectations' were most highly valued by patients. Discrepancies between importance and actual performance during educational nursing consultations were especially found in discussing 'realistic expectations', 'coping information', 'interpersonal communication' and 'tailored communication'.

\subsection{Practice implications}

The results of this study provide tools for the development of interventions supporting both needs assessment and fulfillment to make sure older cancer patients' needs are properly met. Unmet needs assessment is recommended in addition to needs assessement by distinguishing how well needs have been met and identifying those that remains unmet [21]. Specific attention should be paid to role definition between physicians and nurses on communicating prognosis information and realistic expectations. Moreover, generic communication skills could be improved by communication skills training in which attention is paid to better tailoring communication to older cancer patients' needs, interpersonal communication with significant others and providing coping information, ultimately resulting in increased quality of care.

\section{Funding}

This study was funded by the Dutch Cancer Society (grant numbers NIVEL 20032973 and UVA 2010-4740). The Dutch Cancer Society approved the study design, but had no role in the collection, analysis and interpretation of data; in the writing of the report; and in the decision to submit the paper for publication.

\section{Conflict of interest statement}

None declared.

\section{Acknowledgements}

We thank all the patients and nurses who were willing to participate in this study. We very much appreciate the support of the coordinators of the wards for their overall efforts in approaching eligible patients. Furthermore, we thank Mirjam van Dijk, Judith de Groot, Nienke van der Meulen, Janneke Noordman, Jessika Ouwerkerk, Elise Posma and Frank Tol for their help in data gathering and coding of the videotaped consultations.

\section{REFERENCES}

[1] Fallowfield L, Jenkins V. Current concepts of communication skills training in oncology.

Recent Results Cancer Res 2006;168:105-12.

[2] Hack TF, Degner LF, Parker PA. The communication goals and needs of cancer patients: a review. Psychooncology 2005;14:831-45.

[3] American Cancer Society. Cancer facts and Figures 2012, 2012. Downloaded on 11 November, 2012, from http://www.cancer.org/acs/groups/content/@epidemiologysurveilance/documents/document/acspc-031941.pdf. 
Weert, J.C.M. van, Bolle, S., Dulmen, S. van, Jansen, J. Older cancer patients' information and communication needs: what they want is what they get? Patient Education and Counseling. 2013, 92(3), 388-397

[4] Edwards BK, Howe HL, Ries LA, Thun MJ, Rosenberg HM, Yancik R, et al. Annual report to the nation on the status of cancer, 1973-1999, featuring implications of age and aging on U.S. cancer burden. Cancer 2002;94:2766-92.

[5] Given B, Given CW. Older adults and cancer treatment. Cancer 2008;113:3505-11.

[6] Stewart M, Meredith L, Brown JB, Galajda J. The influence of older patient- physician communication on health and health-related outcomes. Clin Geriatr Med 2000;16:25-36.

[7] Brown SC, Park DC. Theoretical models of cognitive aging and implications for translational research in medicine. Gerontologist 2003;43:57-67.

[8] Valentijn SA, van Boxtel MP, van Hooren SA, Bosma H, Beckers HJ, Ponds RW, et al. Change in sensory functioning predicts change in cognitive functioning: results from a 6year follow-up in the Maastricht aging study. J Am Geriatr Soc 2005;53:374-80.

[9] Greene MG, Adelman RD. Physician-older patient communication about can-cer. Patient Educ Couns 2003;62:355-60.

[10] Ingram RE. Information processing and feedback: effects of mood and infor-mation favourability on the cognitive processing of personally relevant infor-mation. Cognit Ther Res 1984;8:371-86.

[11] Petty RE, Cacioppo JT. The elaboration likelihood model of persuasion. In: Berkowitz L, editor. Advances in experimental social psychology. New York: Academic Press; 1986. p. 123-205.

[12] Rimer BK, Kreuter MW. Advancing tailored health communication: a persua-sion and message effects perspective. J Commun 2006;56:S184-201.

[13] Kessels RPC. Patients' memory for medical information. J R Soc Med 2003;96:219-22.

[14] Cameron C. Patient compliance: recognition of factors involved and sugges-tions for promoting compliance with therapeutic regimens. J Adv Nurs 1996;24:244-50.

[15] Ley P. Communicating with patients: improving communication, satisfaction and compliance. New York: Croom Helm; 1988.

[16] Galloway S, Graydon J, Harrison D, Evans-Boyden B, Palmer-Wickham S, Burlein-Hall $\mathrm{S}$, et al. Informational needs of women with a recent diagnosis of breast cancer: development and initial testing of a tool. J Adv Nurs 1997;25:1175-83.

[17] Mossman J, Boudioni M, Slevin ML. Cancer information: a cost-effective intervention. Eur J Cancer 1999;35:1587-91.

[18] Maguire P. Improving communication with cancer patients. Eur J Cancer 1999;35:205865.

[19] Puts MTE, Papoutsis A, Springall E, Tourangeau AE. A systematic review of unmet needs of newly diagnosed older cancer patients undergoing active cancer treatment. Support Care Cancer 2012;20:1377-94.

[20] Jansen J, Weert J, Dulmen S van, Heeren T van, Bensing J. Patient education about treatment in cancer care: an overview of the literature on older patients' needs. Cancer Nurs 2007;30:251-60.

[21] Harrison JD, Young JM, Price MA, Butow PN, Solomon MJ. What are the unmet supportive care needs of people with cancer? A systematic review. Support Care Cancer 2009;17:1117-28.

[22] Dutch Cancer Society. Downloaded on 12 December, 2012, from http:// www.kwf.nl.

[23] McPherson C, Higginson I, Hearn J. Effective methods of giving information in cancer: a systematic literature review of randomized clinical trials. J Public Health Med 2001;23:22734.

[24] Mann KS. Education and health promotion for new patients with cancer: a quality improvement model. Clin J Oncol Nurs 2011;15:55-61.

[25] van den Brink-Muinen, Verhaak PFM, Bensing JM, Bahrs O, Deveugele M, Gask L, et al. Doctor-patient communication in different European health care systems: relevance and performance from the patients' perspective. Patient Educ Couns 2000;39:115-27.

[26] Brouwer W, Sixma H, Triemstra M, Delnoij D. Kwaliteit van zorg rondom een staaroperatie vanuit het perspectief van patie"nten, Meetinstrumentontwik-keling. Quality of care surrounding cataract operation through the eyes of patients. Development of a measurement instrument Utrecht: NIVEL; 2005.

[27] Pieterse A, Van Dulmen S, Ausems M, Schoemaker A, Beemer F, Bensing J. QUOTEGENEca: development of a counselee-centered instrument to measure needs and 
Weert, J.C.M. van, Bolle, S., Dulmen, S. van, Jansen, J. Older cancer patients' information and communication needs: what they want is what they get? Patient Education and Counseling: 2013, 92(3), 388-397

preferences in genetic counselling for hereditary cancer. Psychoon-cology 2005;14:36175.

[28] Sixma HJ, Van Campen C, Kerssens JJ, Peters L. Quality of care from the patients' perspectives: from theoretical concept to a new measuring instrument. Health Expect 1998;1:82-95.

[29] Stubbe JH, Gelsema T, Delnoij DMJ. The consumer quality index hip knee questionnaire measuring patients' experiences with quality of care after a total hip of knee arthroplasty. BMC Health Serv Res 2007;7:60.

[30] Schinkel S, Schouten BC, van Weert JCM. Are GP patients' need being met? Unfulfilled information needs among Dutch and ethnic minority patients. Patient Educ Couns 2013;90:261-7.

[31] Jorgensen ML, Young JM, Harrison JD, Solomon MJ. Unmet supportive care needs in colorectal cancer: differences by age. Support Care Cancer 2012;20:1275-81.

[32] Orimo H, Ito H, Suzuki T, Araki A, Hosoi T, Sawabe M. Reviewing the definition of "elderly". Geriatr Gerontol Int 2006;6:149-58.

[33] Schuurmans H, Steverink N, Lindenberg S, Frieswijk N, Slaets JPJ. Old or frail: what tells us more? J Gerontol 2004;59A:962-5.

[34] Steverink N, Slaets JPJ, Schuurmans H, Van Lis M. Measuring frailty: developing and testing the GFI (Groningen frailty indicator). Gerontologist 2001;41:236.

[35] van Weert JCM, Jansen J, Bruijn GJ, de Noordman J, van Dulmen AM, Bensing JM, QUOTEchemo:. A patient-centered instrument to measure quality of care through the patient's eyes preceding chemotherapy treatment. Eur J Cancer 2009;45:2967-76.

[36] Altman DG. Practical statistics for medical research. London: Chapman \& Hall; 1991.

[37] Bolle S, Muusses LD, Smets EM, Loos EF, van Weert JCM. Chemotherapie, wat weet u er van? Een onderzoek naar de publieke kennis, perceptie van bijwer-kingen, informatiebehoeften en het gebruik van informatiebronnen met betrekking tot chemotherapie. . [Chemotherapy, what do you know about it? A survey of public knowledge, perceptions of side-effects, information needs and the use of information sources related to chemotherapy] Amster-dam: Amsterdam School of Communication Research/ASCoR, Universiteit van Amsterdam; 2012.

[38] Posma E, Van Weert JCM, Jansen J, Bensing JM. Educating older cancer patients: an evaluation through the eyes of patients and professionals. BMC Nurs 2009;8:1.

[39] Mitchell AJ. Reluctance to disclose difficult diagnoses: a narrative review comparing communication by psychiatrists and oncologists. Support Cancer Care 2007;15:819-28.

[40] Schofield P, Carey M, Love A, Nehill C, Wein S. Would you like to talk about your future treatment options? Discussing the transition from curative cancer treatment to palliative care. Palliat Med 2006;20:397-406.

[41] Rutten LJF, Arora NK, Bakos AD, Aziz N, Rowland J. Information needs and sources of information among cancer patients: a systematic review of research (1980-2003). Patient Educ Couns 2005;57:250-61.

[42] Fried TR, Bradley EH, O'Leary J. Prognosis communication in serious illness: perceptions of older patients, caregivers and clinicians. J Am Geriatr Soc 2003;51:1398403.

[43] de Veer A, Francke A, Poortvliet EP. Nurses' involvement in end-of-life deci-sions. Cancer Nurs 2008;33:222-8.

[44] Clayton JM, Hancock KM, Butow PN, Tattersall MHN, Currow DC. Clinical practice guidelines for communicating prognosis and end-of-life issues with adults in the advanced stages of a life-limiting illness, and their caregivers. Med J Aust 2007;186:S77-108.

[45] Mills ME, Sullivan $\mathrm{K}$. The importance of information giving for patients newly diagnosed with cancer: a review of the literature. J Clin Nurs 1999;8:631-42.

[46] Rees CE, Bath PA. The information needs and source preferences of women with breast cancer and their family members: a review of the literature published between 1988 and 1998. J Adv Nurs 2000;31:833-41.

[47] Osse BHP, Vernooij-Dassen MJFJ, Schade E, Grol RPTM. Problems experienced by the informal caregivers of cancer patients and their needs for support. Cancer Nurs 2006;29:378-88. 
Weert, J.C.M. van, Bolle, S., Dulmen, S. van, Jansen, J. Older cancer patients' information and communication needs: what they want is what they get? Patient Education and Counseling: 2013, 92(3), 388-397

[48] Salminen E, Vire J, Poussa T, Knifsund S. Unmet needs in information flow between breast cancer patients, their spouses and physicians. Support Care Cancer 2004;12:6638.

[49] Berg CA, Upchurch R. A developmental-contextual model of couples coping with chronic illness across the adult life span. Psychol Aging 2007;133:920- 54.

[50] Blank TO, Bellizi KM. A gerontological perspective on cancer and aging. Cancer 2008;112:2569-76.

[51] Ganz PA, Lee JJ, Sim MS, Polinsky ML, Schag CA. Exploring the influence of multiple variables on the relationship of age to quality of life in women with breast cancer. J Clin Epidemiol 1992;45:473-85.

[52] Sanson-Fisher R, Girgis A, Boyes A, Bonevski B, Burton L, Cook P. The unmet supportive care needs of patients with cancer, Supportive Care Review Group. Cancer 2000;88:226-37.

[53] Repetto L, Piselli P, Raffaele M, Locatelli C, for the GIOGer. Communication cancer diagnosis and prognosis: when the target is the elderly patient - a GIOGer study. Eur J Cancer 2009;45:374-83.

[54] Capirci C, Feldman-Stewart D, Mandoliti G, Brundage M, Belluco G, Mag- nani K. Information priorities of Italian early-stage prostate cancer patients and of their health-care professionals. Patient Educ Counsel 2005;56: 174-81.

[55] Feldman-Stewart D, Brundage MD, Hayter C, Groome P, Nickel JC, Downes H, Mackillop WJ. What prostate cancer patients should know: variation in professionals' opinions. Radiother Oncol 1998;49:111-23.

[56] Feldman-Stewart D, Capirci C, Brundage MD. Information for patients with early-stage prostate cancer: a comparison of professionals' attitudes in Canada and Italy. Support Cancer care 2003;11:472-80.

[57] Hoeben KWJ, van Steenbergen LN, van de Wouw AJ, Rutten HJ, van Spronsen DJ, Janssen-Heijnen MLG. Treatment and complications in elderly stage III colon cancer patients in the Netherlands. Ann Oncol 2012. Advance online publication.

\section{TABLES AND FIGURES}

\begin{tabular}{|c|c|c|c|c|}
\hline Category & Number of items & Content & $\begin{array}{l}\text { Cronbact's } \alpha \\
\text { QUOTE } \\
\text { Importance } \\
\text { (questionnaires) }\end{array}$ & $\begin{array}{l}\text { Cronbach's } \alpha \\
\text { QUOTE }^{\text {chemo }} \\
\text { Performance } \\
\text { (video observations) }\end{array}$ \\
\hline \multicolumn{5}{|l|}{ Cancer-specific categories } \\
\hline Treatment-related information & 19 & $\begin{array}{l}\text { Purpose of treatment; how treatment works; treatment plan, } \\
\text { description, logistic information, tests and procedures, hospital } \\
\text { routines; side effects and physical effects of treatment; } \\
\text { influence of treatment on sexuality; where to get information } \\
\text { about treatment }\end{array}$ & 0.92 & 0.92 \\
\hline Realistic expectations & 3 & $\begin{array}{l}\text { Expected life span or survival rate; discussing the future (e.g. } \\
\text { effect on life plan or long term goals); what will happen if } \\
\text { patient chooses not to start CT treatment }\end{array}$ & 0.70 & 0.72 \\
\hline Rehabilitation information & 11 & $\begin{array}{l}\text { Self-care issues during treatment and recovery; dealing with } \\
\text { side effects at home; nutrition, effects on social life, leisure, } \\
\text { employment or work life, health behavior and promotion }\end{array}$ & 0.85 & 0.87 \\
\hline \multicolumn{5}{|c|}{ Generic communication skilk categories } \\
\hline Coping information & 7 & $\begin{array}{l}\text { Coping with cancer and treatment; exploring the patients' } \\
\text { feelings and emotions; community counseling or support; } \\
\text { support from other patients }\end{array}$ & 0.85 & 0.82 \\
\hline Interpersonal communication & 6 & $\begin{array}{l}\text { Effect of treatment on significant others, i.e. family members or } \\
\text { friends; attention to significant others; exploring support } \\
\text { needs of significant others }\end{array}$ & 0.89 & 0.72 \\
\hline Tailored communication & 10 & $\begin{array}{l}\text { Communication skills to provide personalized information and } \\
\text { tailor the information to the patients' individual needs; } \\
\text { knowledge of and adaptation to the patients personal situation } \\
\text { and preferences }\end{array}$ & 0.83 & 0.71 \\
\hline Affective communication & 10 & $\begin{array}{l}\text { Establishing a trusting relationship between provider and } \\
\text { patient, eg. by empathizing, giving attention and emotional } \\
\text { support, listening }\end{array}$ & 0.89 & 0.88 \\
\hline
\end{tabular}

Based on patient questionnaires $(n=116)$. 
Weert, J.C.M. van, Bolle, S., Dulmen, S. van, Jansen, J. Older cancer patients' information and communication needs: what they want is what they get? Patient Education and Counseling: 2013, 92(3), 388-397

Table 2

Characteristics of the total group of participating patients $(N-155)$ and completers of the QUOTE ${ }^{\text {chemo }}$-Importance $(n-116)$.

\begin{tabular}{|c|c|c|c|c|c|}
\hline & \multicolumn{2}{|c|}{ Total group $(N=155)$} & \multicolumn{2}{|c|}{$\begin{array}{l}\text { Completers } \text { QUOTE }^{\text {chemo }} \text {-Im- } \\
\text { portance }(n-116)\end{array}$} & \multirow[t]{2}{*}{$p^{2}$} \\
\hline & $n^{\mathrm{b}}$ & $\%$ & $\pi^{\mathrm{b}}$ & $\%$ & \\
\hline Gender & & & & & 0.506 \\
\hline Male & 106 & 68.4 & 81 & 69.8 & \\
\hline Female & 49 & 31.6 & 35 & 30.2 & \\
\hline Age & & & & & 0.408 \\
\hline$M(S D)$ & \multirow{2}{*}{\multicolumn{2}{|c|}{$\begin{array}{c}72.1(4.5) \\
(65.0-85.7)\end{array}$}} & \multicolumn{2}{|c|}{$\begin{array}{c}71.9(4.4) \\
(65.0-85.0)\end{array}$} & \\
\hline Range & & & & & \\
\hline Educational level & & & & & 0.139 \\
\hline Low & 76 & 50.0 & 54 & 47.3 & \\
\hline Middle & 27 & 17.8 & 24 & 21.1 & \\
\hline High & 49 & 32.2 & 36 & 31.6 & \\
\hline Living arrangements & & & & & 0.020 \\
\hline Alone & 33 & 21.7 & 18 & 15.7 & \\
\hline With partner & 108 & 71.9 & 89 & 77.4 & \\
\hline With partner and child(ren) & 6 & 3.9 & 4 & 3.5 & \\
\hline With child(ren) & 3 & 2.0 & 2 & 1.7 & \\
\hline Other & 2 & 1.3 & 2 & 1.7 & \\
\hline Primary tumor site & & & & & 0.264 \\
\hline Breast & 12 & 7.7 & 9 & 7.9 & \\
\hline Digestive-gastrointestinal & 60 & 38.7 & 47 & 41.2 & \\
\hline Hematologic & 15 & 9.7 & 14 & 12.3 & \\
\hline Lung & 42 & 27.1 & 26 & 22.8 & \\
\hline Gynecological & 6 & 3.9 & 4 & 3.5 & \\
\hline Genitourinar & 16 & 10.3 & 12 & 10.5 & \\
\hline Other & 2 & 1.3 & 2 & 1.8 & \\
\hline Time since diagnosis (months) & & & & & 0.458 \\
\hline$M(\mathrm{SD})$ & & & & & \\
\hline Treatment intent & & & & & 0.107 \\
\hline Curative & 39 & 25.2 & 32 & 27.6 & \\
\hline Palliative & 88 & 56.8 & 60 & 51.7 & \\
\hline Unknown & 28 & 18.1 & 24 & 20.7 & \\
\hline Frailty (GFI; $\underline{0}-15)^{c}$ & & & & & 0.001 \\
\hline$M(S D)$ & & & & & \\
\hline
\end{tabular}


Weert, J.C.M. van, Bolle, S., Dulmen, S. van, Jansen, J. Older cancer patients' information and communication needs: what they want is what they get? Patient Education and Counseling: 2013, 92(3), 388-397

\section{Table 3}

Characteristics of nur ses who completed the QUOTE ${ }^{\text {themo }}$-Importance $(n=123)$.

\begin{tabular}{|c|c|c|}
\hline & $n^{2}$ & \% \\
\hline \multicolumn{3}{|l|}{ Gender } \\
\hline Female & 114 & 93.4 \\
\hline Male & 8 & 6.6 \\
\hline \multicolumn{3}{|l|}{ Age } \\
\hline$M(\mathrm{SD})$ & $41.0(8.1)$ & \\
\hline \multicolumn{3}{|l|}{ Experience as a nurse (years) } \\
\hline$M(S D)$ & $17.1(8.2)$ & \\
\hline \multicolumn{3}{|l|}{ Experience in oncology } \\
\hline$M(\mathrm{SD})$ & $11.8(7.5)$ & \\
\hline \multicolumn{3}{|l|}{ Employed on this ward (years) } \\
\hline$M(S D)$ & $10.1(7.7)$ & \\
\hline \multicolumn{3}{|l|}{ Position } \\
\hline Nurse & 13 & 10.7 \\
\hline Nurse being educated for oncology nurse & 7 & 5.7 \\
\hline Oncology nurse & 66 & 54.1 \\
\hline Spedalized oncology nurse & 13 & 10.7 \\
\hline Nurse practioner or research nurse & 6 & 4.9 \\
\hline Other & 17 & 14.0 \\
\hline
\end{tabular}

a $n$ varies slightly due to missing data.

Figure 1. percentages of cancer-specific categories scored as (very) important by patients and nurses resp. discussed during consultation (mean score $>2.5$ ) 
Weert, J.C.M. van, Bolle, S., Dulmen, S. van, Jansen, J. Older cancer patients' information and communication needs: what they want is what they get? Patient Education and Counseling: 2013, 92(3), 388-397

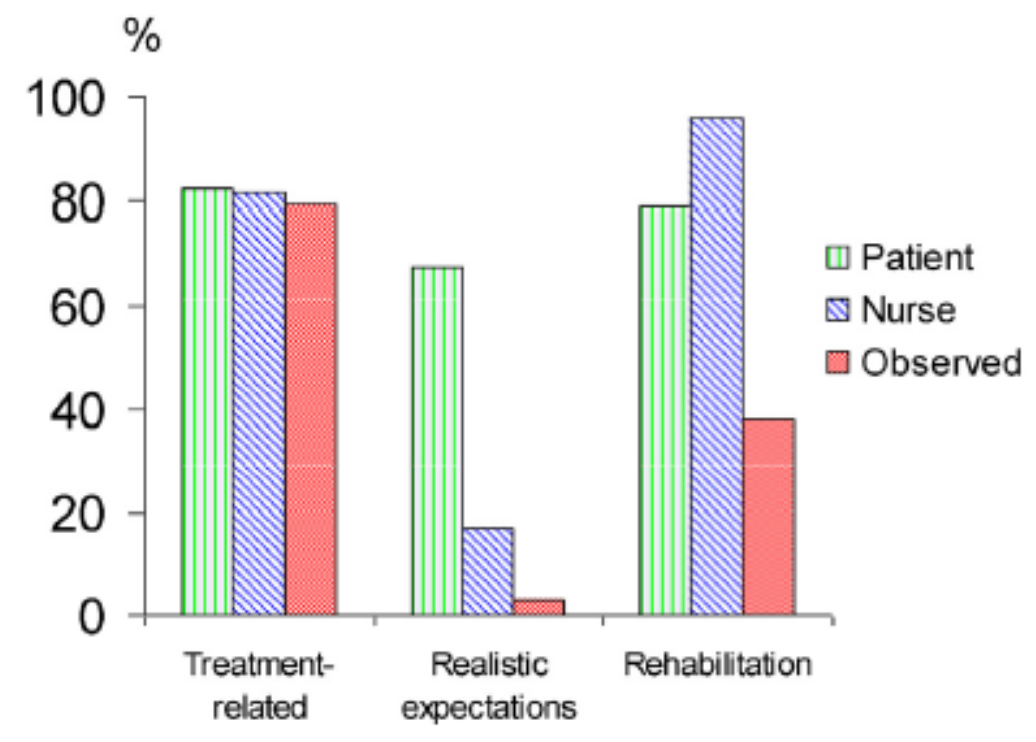


Weert, J.C.M. van, Bolle, S., Dulmen, S. van, Jansen, J. Older cancer patients' information and communication needs: what they want is what they get? Patient Education and Counseling: 2013, 92(3), 388-397

Table 4

Mean Importance scores of nurses and patients, mean Performance scores and mean quality impact indices (Qlis).

\begin{tabular}{|c|c|c|c|c|c|c|c|}
\hline Number & Item description & $\begin{array}{l}\text { Mean } \\
\text { Importance } \\
\text { score nurses }\end{array}$ & $\begin{array}{l}\text { Mean } \\
\text { Importance } \\
\text { score patients }\end{array}$ & $\begin{array}{l}\text { Mean } \\
\text { Performance } \\
\text { scare }\end{array}$ & $\begin{array}{l}\text { Q lack of } \\
\text { Performance } \\
\text { (score } 1 \text { or } 2 \text { ) }\end{array}$ & $\begin{array}{l}\text { Mean } \\
\text { QIP }\end{array}$ & $(S D)$ \\
\hline \multicolumn{8}{|c|}{ Cance-sperific iscues } \\
\hline F1 & Treatment-related information & $279(0.41)^{\mathrm{n}^{*}}$ & $2.97(0.48)^{2}$ & $2.83(0.35)$ & 36.1 & 1.07 & $(0.17)$ \\
\hline Q1 & Aim of treatment & $290(089)^{\prime \prime}$ & $3.17(0.65)^{f}$ & $2.62(096)^{4}$ & 42.6 & 135 & $(028)$ \\
\hline$Q 2$ & Discussion of possible side effects of treatment & $301(0.38)$ & $3.18(0.71)$ & $302(0.71)$ & 20.0 & 0.64 & (0.14) \\
\hline 09 & Risk of infections during treatment & $3.48(0.55)$ & $3.31(0.64)$ & $3.47(0.83)$ & 11.6 & 038 & $(007)$ \\
\hline Q11 & Low white blood cell count & $295(0.80)$ & $306(0.76)$ & $308(0.90)$ & 21.1 & $a 71$ & $(0.18)$ \\
\hline Q12 & Number of blood tests needed & $3.12(0.67)$ & $320(0.65)$ & $321(0.89)$ & 18.1 & ass & $(0.12)$ \\
\hline Q13 & Hospital procedures and logistical information & $285(0.77)^{*}$ & $2.69(0.82)$ & $2.54(0.90)^{2}=$ & 46.5 & 1.25 & $(0.38)$ \\
\hline Q14 & Sufficient information about what is going on & $233(0.95)^{\mathrm{nc} c}$ & $3.16(0.73)^{x}=$ & $136(0.93)^{4}$ & 78.7 & 2.48 & $(0.57)$ \\
\hline Q15 & Increased risk of getting bruises and nose bleects & $3.11(0.69)^{6}$ & $299(0.67)$ & $281(1.19)^{*}$ & 35.5 & 1.06 & $(0.24)$ \\
\hline Q18 & Influence of treatment an the development of cancer cells & $209(0.91)^{\mathrm{nec}}$ & $308(0.85)^{4}$ & $2.51(1.03)^{-b}$ & 46.5 & 1.43 & $(0.39)$ \\
\hline Q19 & How often you need to came to the hos pital & $220(081)^{p}$ & $238(0.79)^{4}$ & 229 (0.85) & 60.0 & 1.67 & $(0.47)$ \\
\hline 020 & When you should contact the hos pital & $384(0.39)^{2 / C}$ & $352(0.60)$ & $3.46(0.74)^{3}$ & 11.7 & 0.41 & $(007)$ \\
\hline Q2s & Order in which medicines are administered & $1.90(0.90)^{\mathrm{anc}}$ & $283(0.90)^{4}$ & $289(1.12)^{*}$ & 33.5 & 0.95 & $(0.30)$ \\
\hline 044 & How the mectidnes spread through the bloodstrean & $1.93(0.89)^{\mathrm{b}}$ & $2.56(0.91)^{\mu, c}$ & $168(0.87)^{P}$ & 85.2 & 218 & $(0.38)$ \\
\hline 051 & Sufficient information about chemotherapy trexment & $325(0.73)^{6}$ & 3.19 (a.62f & $232(0.58)^{4}$ & 31.6 & 1.01 & $(020)$ \\
\hline 052 & Length of chemotherapy treatment & $258(0.89)^{\mathrm{m} c}$ & $3.11(0.9)$ & $3.19(0.84)$ & 18.3 & ast & $(0.13)$ \\
\hline 056 & Influence on sexuality & $265(0.08)^{2} \mathrm{c}$ & $185(093)^{4} c^{\prime}=$ & $223(1.14)^{a n a}=$ & 53.5 & 0.99 & $(0.50)$ \\
\hline $0 \% 9$ & How chemotherapy is administered & $234(0.91)^{f}$ & $2.53(1.00)$ & $296(0.93)^{2}$ & 29.2 & a.74 & $(029)$ \\
\hline 060 & Which members of hospital team can ars wer questions & $3.43(0.63)^{\mathrm{b}}$ & $305(0.82)^{4}=$ & $3.50(0.82)$ & 10.5 & 32 & $(009)$ \\
\hline Q64 & Treatments that can reduce side effects & $302(0.65)^{6}=$ & $3.16(0.65)$ & $235(0.74)^{4}$ & 31.6 & 1.00 & $(020)$ \\
\hline $\mathbf{F}$ & Realistic expecdationsprognosis information & $1.76(0.63)^{\text {he }}$ & $2.83(0.78)^{2}$ & $1.25(0.48)^{4 / 4}$ & 91.4 & 259 & $(0.71)$ \\
\hline$Q 22$ & $\begin{array}{l}\text { What will happen if patient chooses not to start } \\
\text { treatment }\end{array}$ & $1.83(0.86)^{4 . e}$ & $321(0.88)^{2}$ & $120(0.66)^{4}$ & 929 & 298 & $(081)$ \\
\hline$Q 24$ & Expected survival & $1.39(0.60)^{p}$ & $236(1.09)^{\mathrm{n}, \mathrm{c}}$ & $130(\alpha, 71)^{p}$ & 88.4 & 244 & $(096)$ \\
\hline$Q 50$ & Discussing the future & $210(083)^{\mathrm{n}-1} e$ & $2.46(1.03)^{\mathrm{A}}-\mathrm{e}$ & $124(0.57)^{4}$ & 929 & 229 & $(096)$ \\
\hline $\mathbf{F} 2$ & Rehabilitation information,dealing with treatment at home & $3.12(0.90)^{a / c}$ & $2.87(0.45)^{4}$ & $\left.2.33(0.49)^{2}\right)$ & 519 & 1.49 & $(0.23)$ \\
\hline 05 & Preventing or reducing side-effects at home & $3.63(0.52)^{\mathrm{mec}}$ & $3.31(0.58)^{4}$ & $230(0.65)^{4}$ & 32.7 & 1.08 & $(0.19)$ \\
\hline Q10 & Impact of treatment on activities of daily living & $328(0.53)^{\mathrm{m} *} \mathrm{~F}$ & $304(0.57)^{4} \%$ & $191(0.94)^{1 / 2}$ & 67.1 & 204 & $(0.38)$ \\
\hline 023 & Necessity of home care during treatment & $309(0.98)^{\mathrm{a} e}$ & $2.45(0.82)$ & $165(1.01)^{\mathrm{ath}}$ & 78.7 & 193 & $(0.64)$ \\
\hline 027 & Prevention of mouth ukers & $3.42(0.56)^{2}-/=$ & $309(0.62)^{2}=$ & $3.12(1.04)^{4}=$ & 25.3 & a.78 & $(0.16)$ \\
\hline$Q_{30}$ & Possibilities to do pleasant things during treatment period & $272(0.73)^{\mathrm{n} *}=$ & $2.41(0.92)^{4} \%$ & $135(1.02)^{\mathrm{a} . \mathrm{b}}$ & 735 & 1.77 & (0.68) \\
\hline $\mathrm{cos}_{2}$ & Dietary advice during treatment & $268(0.84)^{2}$ & $302(0.73)^{4}$. & $292(097)$ & 29.7 & 090 & $(022)$ \\
\hline$Q 33$ & Mansying fatigue & $3.16(0.59)^{\mathrm{an}} / \mathrm{F}$ & $2.85(0.70)^{*}$ & $260(1.13)$ & 43.2 & 1.23 & $(0.30)$ \\
\hline 099 & Consequences of treatment for patients" daily life & $299(0.56)^{e}$ & 236 (a)sf & 179 (a.89) & 72.7 & 201 & $(0.49)$ \\
\hline 042 & How to deal with diarrhea or constipation & $3.23(0.64)^{f}$ & $3.19(0.59)^{f}$ & $2.36(1.05)^{4}$ & 50.0 & 1.60 & $(0.30)$ \\
\hline 061 & How to deal with urine, feces and vomit & $323(0.57)$ & $3.11(0.74)$ & $3.30(0.99)$ & 14.8 & 0.46 & $(0.11)$ \\
\hline Q66 & $\begin{array}{l}\text { Pessibilities to continue work life or leisure } \\
\text { during treatment }\end{array}$ & $278(0.68)^{\mathrm{a} e}$ & 227 (a.s8) & $1.49(0.89)^{4}$ & 83.2 & 1.89 & $(0.33)$ \\
\hline \multicolumn{8}{|c|}{ Ceraic isues } \\
\hline $\mathbf{F 6}$ & Coping information & $290(0.46)^{2 a c}$ & $2.34(0.63)^{2.5}$ & $1.75(0.48)^{45}$ & 76.5 & 1.79 & $(0.48)$ \\
\hline 026 & Explaring the patients' feelings about treatment & $338(0.58)^{4}=$ & $232(0.74)^{\mu}=$ & $196(1.07)^{4,6}$ & 72.3 & 196 & $(0.54)$ \\
\hline Q28 & Explaining emotional reactions on chemother $a y$ treatment & $253(0.76)^{\mathrm{m}} * \mathrm{~F}$ & $278(0.85)^{4} \%$ & $1.12(0.39)^{\mathrm{m}}$ & 97.4 & 271 & $(0.83)$ \\
\hline Q38 & Support from other patients or support groups & $266(0.70)^{2}$ & $180(0.86)^{4} c^{*}$ & $150(1.05)^{4} \mathrm{~m}^{*}$ & 82.6 & 1.48 & $(0.31)$ \\
\hline 047 & Psychosocial care & $297(0.69)^{\mathrm{m} e}$ & $2.38(0.90)^{3}$ & $227(1.40)^{\circ}$ & 55.8 & 133 & $(0.50)$ \\
\hline 048 & Exploring the patients worries and anxieties & $330(0.58)^{2} \mathrm{c}$ & $2.40(0.93)^{4} \mathrm{c}$ & $202(0.84)^{4}$ & 70.3 & 1.09 & $(0.65)$ \\
\hline 05 & Alternative or complementary therapies & $253(0.77)^{\mathrm{me}}$ & $2.11(0.92)^{\mu}=$ & $1.17\left(a_{89}\right)^{4}$ & 94.8 & 200 & $(087)$ \\
\hline Q58 & How to get emotional support from others & $297(0.62)^{2} c$ & $2.13(0.90)^{p}$ & $2.19(1.01)^{x}$ & 62.6 & 133 & $(0.56)$ \\
\hline FS & Interpersonal communication & $296(0.47)^{\mathrm{n}+* / /}$ & $2.55(0.78)^{2 * * / f}$ & $\left.2.06(0.56)^{4}\right)$ & 64.7 & 1.73 & $(0.46)$ \\
\hline Q34 & Being attentive to significant others & $326(0.58)^{3}$ & $266(0.94)^{\mu} \mathrm{c}$ & $3.45(1.75)^{3}$ & 27.5 & $a 73$ & $(026)$ \\
\hline Q45 & Explaring questions of significant others & $294(0.64)$ & $270(0.90)$ & $305(1.97)$ & 47.4 & 1.28 & $(0.43)$ \\
\hline 049 & $\begin{array}{l}\text { Discussing how patient and significant others can cope with } \\
\text { treatment together }\end{array}$ & $296(0.62)^{f}$ & 231 (0.8s) & $2.46(0.98)^{a b}$ & 75.0 & 203 & $(0.66)$ \\
\hline Q53 & Explaring support needs of significant others & $300(0.65)^{f^{\prime \prime}}$ & $253(096)$ & $2.34(223)^{2=}$ & 76.8 & 194 & $(0.34)$ \\
\hline Q62 & Adapting to the needs and wishes of significant others & $283(0.70)$ & 258 (0.92) & $2.65(209)$ & 75.9 & 196 & $(0.69)$ \\
\hline Q67 & $\begin{array}{l}\text { Discussing how significant others mig ht provide } \\
\text { emotional support }\end{array}$ & $276(0.63)^{4}$ & $2.35(0.94)$ & $222(223)^{*}$ & 85.4 & 200 & $(080)$ \\
\hline $\mathbf{F}$ & Tailored communication & $3.07(0.35)^{\mathrm{hac}}$ & $2.69(0.54)^{4}$ & $1.90(0.33)^{20}$ & 63.9 & 1.72 & (0.34) \\
\hline Q6 & Asking how much information the patient would like to know & $3.15(0.78)^{2 n-1 /}=$ & $285(0.75)^{-1}=$ & $1.15(0.49)^{3.5}$ & 96.1 & 274 & $(0.32)$ \\
\hline cos & Checking what information the paient a ready knows & $324(0.64)^{4}=$ & $2.36(0.86)^{4}=$ & $2.40(1.10)^{n}$ & 55.8 & 154 & $(0.48)$ \\
\hline Q16 & Understanding the patients' personal circumstances & $315(0.63)^{\mathrm{me}}$ & $234(0.81)^{4}=$ & $131(\arg )^{4}$ & 87.7 & 240 & $(0.31)$ \\
\hline Q17 & Checking the patients' expectations & $3.10(0.61)^{\mathrm{a}-e}$ & $278(0.89)^{4}-c$ & $1.43(a .77)^{4}$ & 88.4 & 246 & $(0.38)$ \\
\hline 009 & Checking patients' preferences for trexment & $224(0.76)^{6}$ & $2.19(096)^{f}$ & $155(098)^{n}$ & 80.0 & 1.75 & $(0.37)$ \\
\hline$Q 31$ & $\begin{array}{l}\text { Checking whether the patient still wants to start } \mathrm{Cr} \\
\text { after being educated }\end{array}$ & $215(0.93)^{4 a c}$ & $274(1.00)^{4}$ & $1.10(0.43)^{-10}$ & 96.8 & 265 & $(0.97)$ \\
\hline Q35 & Considering the patients' arrent capabilities & $3.27(0.58)^{2}=$ & $2.57(0.81)^{4}$ & $2.63(\alpha .79)^{4}$ & 32.3 & a.s3 & $(026)$ \\
\hline 097 & Checking the patients' knowledge about chemotherapy & $318(0.60)^{a} \mathrm{c}$ & 2.37 (0.86) & $1.99(1.14)^{4 / 2} \cdot{ }^{*}$ & 67.1 & 1.59 & $(0.58)$ \\
\hline Q41 & $\begin{array}{l}\text { Tailoring the information to the patients" personal } \\
\text { circumstances }\end{array}$ & $3.42(0.57)^{\mathrm{n} e}$ & $268(0.82)^{3}$ & $261(0.79)^{3}$ & 40.0 & 1.07 & $(0.33)$ \\
\hline Q6S & Checking the patients' understanding of information & $3.73(0.45)^{\mathrm{a} e}$ & $3.16(0.66)^{2} \mathrm{ec}$ & $2.46(0.96)^{4, b}$ & 523 & 1.65 & $(0.34)$ \\
\hline
\end{tabular}


Weert, J.C.M. van, Bolle, S., Dulmen, S. van, Jansen, J. Older cancer patients' information and communication needs: what they want is what they get? Patient Education and Counseling: 2013, 92(3), 388-397

Table 4 (Continued)

\begin{tabular}{|c|c|c|c|c|c|c|c|}
\hline Number & Item description & $\begin{array}{l}\text { Mean } \\
\text { Importance } \\
\text { score nurses }\end{array}$ & $\begin{array}{l}\text { Mean } \\
\text { Impor tance } \\
\text { score patients }\end{array}$ & $\begin{array}{l}\text { Mean } \\
\text { Performance } \\
\text { score }\end{array}$ & $\begin{array}{l}\text { X. ladk of } \\
\text { Performance } \\
\text { (score } 1 \text { or } 2 \text { ) }\end{array}$ & $\begin{array}{l}\text { Mean } \\
\text { QIP }\end{array}$ & $(\mathrm{SD})$ \\
\hline F7 & Affective communication & $3.42(0.36)^{4 a c}$ & $2.85(0.50)^{4}=$ & $3.07(0.55)^{4}, \cdots$ & 22.5 & 0.64 & (0.11) \\
\hline $\mathscr{Q P}$ & Listening carefully to questions & $378(0.41)^{b / f}$ & $321(0.60)^{\mathrm{Ac}}$ & $3.49(0.60)^{+h}$ & 5.2 & a.17 & (0.03) \\
\hline 021 & Being attentive to how the patient is doing & $\left.3.60(0.52)^{2}\right)^{c}$ & $279(0.64)^{\mathrm{s}}$ & $2.97(0.96)^{3}$ & 25.2 & $a \times 0$ & (0.16) \\
\hline Q36 & Paying attention to the patient & $3.48(0.55)^{b / f}$ & $2.62(0.78)$ & $2.82(0.73)^{3}$ & 34.2 & 090 & $(027)$ \\
\hline Q40 & Showing empathy & $3.19(0.61)^{\mathrm{b}, \mathrm{e}}$ & $2.37(0.76)^{2}$ & $2.84(0.83)^{4}$ & 32.3 & a.76 & (025) \\
\hline Q43 & Being kind & $3.44(0.56)^{m}$ & $3.17(0.68)^{a c}$ & $3.51(0.60)^{b}$ & 5.2 & a.17 & $(004)$ \\
\hline 046 & Lending a listering ear & $3.48(0.5)^{3}, 8$ & $285(0.66)^{3}$ & $3.01(0.86)^{5}$ & 26.5 & $a \times 6$ & $(0.17)$ \\
\hline 054 & Being open & $330(0.59)^{\mathrm{f}}$ & $324(a, 72 f$ & $2.87(0.72)^{4}$ & 26.5 & a.96 & (0.19) \\
\hline$\$ 57$ & Providing space for feelings and emotions & $3.47(0.53)^{b, f}$ & $2.50(0.84)^{4}$ & $2.70(0.88)^{3}$ & 39.4 & 098 & $(0.33)$ \\
\hline 063 & Tailoring inform xion to the patient's situation & $3.10(0.59)^{b}$ & $2.70(0.74)^{4 c}$ & $3.14(\alpha 77)^{b}$ & 20.1 & a.54 & (0.15) \\
\hline 068 & Taking time & $337(0.53)^{\mathrm{m}}$ & $301(0.67)^{\mathrm{ac}}$ & $337(0.67)^{p}$ & 10.3 & a.31 & $(007)$ \\
\hline
\end{tabular}

QII - quality impact indices based on patients' importancs score and performance score (scores $\geq 1.00$ indicatea clear nead for improvement; the higher the score, the more discrepancies between Importance and Performance,

A Significant different from mean importance score of nurses ( $p<0001$ unless otherwise stated directly after.

b Significant different from mean importance score of patients $(p<0.001$ unless otherwise stated directly after.

¿. Sigrificant different from mean performance score $(p<0.001$ unless otherwise stated directly after.

$-p<005$

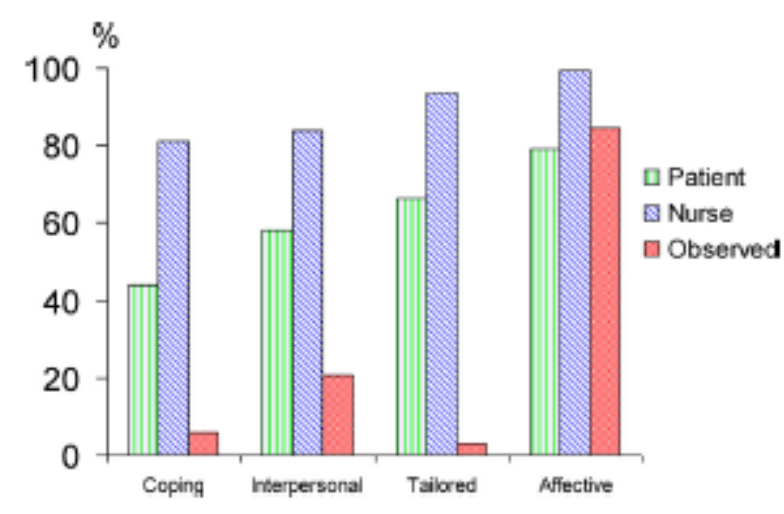

Fig 2. Percentages of genericcategaries scored as (very) important by patients and nurses resp. discussed during consultation (mean score $\geq 25$ ) 